\title{
Is there an optimal management for localized prostate cancer?
}

This article was published in the following Dove Press journal:

Clinical Interventions in Aging

2 July 2010

Number of times this article has been viewed

\author{
Jaspreet Singh \\ Edouard J Trabulsi \\ Leonard G Gomella \\ Department of Urology Kimmel \\ Cancer Center Thomas Jefferson \\ University Philadelphia, PA, USA
}

Correspondence: Leonard Gomella Department of Urology,

Thomas Jefferson University,

Philadelphia, PA 1025 Walnut Street,

Suite 1112 Philadelphia, PA 19107, USA

Tel + I 2I5955 696 I

$\mathrm{Fax}+\mid \mathrm{I} 2159231884$

Email leonard.gomella@jefferson.edu
Abstract: Widespread screening with prostate-specific antigen (PSA) has led to a significant increase in the detection of early stage, clinically localized prostate cancer (CaP). Various treatment options for localized $\mathrm{CaP}$ are discussed in this review article including active surveillance, radical prostatectomy, radiation therapy, and cyrotherapy. The paucity of high-level evidence adds a considerable amount of controversy when choosing the "optimal" intervention, for both the treating physician and the patient. The long time course of $\mathrm{CaP}$ intervention outcomes, combined with continuing modifications in treatments, further complicate the matter. Lacking randomized trials that compare treatment options, this review article attempts to summarize the different treatment options and associated side-effects, including effects on health-related quality of life, from current published literature.

Keywords: prostate cancer, PSA, detection

\section{Introduction}

One of the major challenges in caring for men with newly diagnosed prostate cancer $(\mathrm{CaP})$ is deciding between the many treatment options available. Often, a patient with newly diagnosed localized CaP seeks the "right" answer from his treating physicians. In fact, short of encouraging participation in clinical trials, it is difficult to define the "optimal" way to treat localized CaP. Currently, the treatment of localized $\mathrm{CaP}$ remains controversial. This controversy is highlighted by a recent specialist survey on the "optimal" treatment of a hypothetical patient with localized CaP: approximately $29 \%$ favored expectant management, $33 \%$ favored radiotherapy and $39 \%$ chose radical prostatectomy. ${ }^{1}$ The lack of consensus amongst experts underscores how important it is for men diagnosed with $\mathrm{CaP}$ to make an informed treatment decision through an objective discussion of the risks and benefits of each approach. In planning a treatment, the burden typically falls upon the primary diagnosing physician, most commonly the urologist, to discuss with the patient both the choice of intervention and also the concerns of quality of life and longevity. Each treatment often carries unique potential for side effects, variable long term cancer control data. The long time course of $\mathrm{CaP}$ intervention outcomes combined with continuing modifications in treatments further complicate the matter.

This article will discuss surgical and nonsurgical options available for the treatment of newly diagnosed localized $\mathrm{CaP}$ and will highlight some of the advances in each area. For patients with low-volume and low-grade cancer, characteristics typically associated with minimal risk of cancer progression, a considerable controversy exists regarding the optimal treatment, including whether to treat at all. Finding the right 
approach for treating high risk $\mathrm{CaP}$ is also difficult. However, while monotherapy with radical prostatectomy or radiation may be adequate for some men, there are randomized trials suggesting the need for a multi-modal approach to a more aggressive high risk cancer.

\section{Risk stratification}

D'Amico and colleagues developed the concept of risk stratification, allowing the classification of men into low-, intermediate-, and high-risk pretreatment groups using a combination of clinical data: prostate-specific antigen (PSA), Gleason sum, and clinical stage (Table 1). ${ }^{2}$ The classification was originally developed to estimate the risk of biochemical recurrence following treatment for localized $\mathrm{CaP}$ and has become an important component in treatment recommendations. Other methods such as the Partin tables or Kattan nomograms may help guide therapy as they suggest the probability of organ confined disease or if the cancer has spread outside the prostate. ${ }^{3}$ In the current era of multimodality therapy, this data may help guide treatment choices as well as create realistic expectations on the probability that a single treatment would be successful or if a combined approach is likely to be necessary.

Additional patient specific data may aid in determining the aggressiveness of $\mathrm{CaP}$ and guide recommendations towards the best treatment option. For example, a rise of PSA $>2.0 \mathrm{ng} / \mathrm{mL} /$ year before radical prostatectomy was a predictor for $\mathrm{CaP}$ mortality with a $15 \% \mathrm{CaP}$ mortality rate at 7 years. No patients with a PSA rise of $<2.0 \mathrm{ng} / \mathrm{mL} / \mathrm{year}$ before surgery died from CaP. This rise of $>2.0 \mathrm{ng} / \mathrm{mL} / \mathrm{year}$ identifies a group of patients with aggressive and potentially life threatening $\mathrm{CaP}^{4}$ A PSA density $>0.15 \mathrm{ng} / \mathrm{mL} / \mathrm{cm}^{3}$ predicted those more likely to receive active treatment after active surveillance (AS). ${ }^{5}$ These studies suggest that clinical data including PSA kinetics may identify patients at elevated risk of disease progression and have a potential role in patient counseling in favor or against specific therapy.

\section{Active surveillance and watchful waiting}

Growing in popularity are "treatment" approaches for localized, asymptomatic $\mathrm{CaP}$ that do not involve an active intervention: active surveillance and watchful waiting (WW).

Table I D'Amico risk stratification of prostate cancer ${ }^{2}$

\begin{tabular}{llll}
\hline & PSA $\mathbf{n g} / \mathbf{m L}$ & Gleason sum & Clinical stage \\
\hline Low risk & $\leq 10$ & $\leq 6$ & $\leq \mathrm{T} 2 \mathrm{a}$ \\
Intermediate risk & $10-20$ & 7 & T2b \\
High risk & $\geq 20$ & $8-10$ & $\geq \mathrm{T} 2 \mathrm{c}$ \\
\hline
\end{tabular}

While similar, there are distinct differences. Watchful waiting is now considered the intent to treat only if, or when, metastases or symptomatic progression appears. This is usually limited to asymptomatic men with limited life expectancy who often have high grade tumors. Contemporary AS protocols aim to treat, with curative intent, those prostate cancers that develop more aggressive features during a period of surveillance and while the $\mathrm{CaP}$ is still amenable to definitive therapy such as surgery or radiotherapy. While there is no uniform consensus at present, AS generally involves periodic follow up examinations, PSA testing and repeat biopsy.

Advocates of AS argue that $\mathrm{CaP}$ is over treated in the United States. There is a glaring discrepancy between the number of patients diagnosed with $\mathrm{CaP}$ and the number of men that will die from this disease. There is a $16 \%$ lifetime risk of being diagnosed with CaP but only a $3 \%$ lifetime risk of dying from it. ${ }^{6}$ Autopsy data shows that despite the presence of $\mathrm{CaP}$ in one-third of men over age 60 and up to $50 \%$ of men over 70 , men in the United States are more likely to die of other comorbid conditions. ${ }^{7}$ Knowledge of the natural history of low-risk CaP has also improved. Parker, et al estimated that the 15-year CaP specific mortality for conservative management of screen detected $\mathrm{CaP}$ was $0 \%-2 \%$ if the Gleason score were $<7 .{ }^{8}$ Data from the recently completed European Randomized Study of Screening for Prostate Cancer, estimated the lead time associated with PSA screening to be 10.3 years and the over diagnosis rate to be $54 \% .{ }^{9}$ These studies highlight the need to identify more definitive factors to distinguish insignificant disease from that which will result in disease specific morbidity and mortality.

One of the challenges of an AS protocol is the concern of under sampling and inadequate mapping of the volume of cancer present. An AS study from MD Anderson Cancer Center demonstrated very low upstaging at the time of prostatectomy and that all specimens had organ confined tumor. The transition zone was involved in $29 \%$ of unifocal and $71 \%$ of multifocal tumors. ${ }^{10}$ Therefore when instituting an AS program, a repeat biopsy is usually recommended. Despite these findings, van den Bergh et al have shown that delayed intervention within 2 years does not have worse pathologic features compared to patients who undergo immediate radical prostatectomy. ${ }^{11}$ Only a small percentage of patients on AS will show signs of disease progression, with an estimated risk of metastasis of $<1 \%$ at 2 to 8 years while on surveillance. ${ }^{11,12,13}$ Also, patients with low-risk features (PSA $<10 \mathrm{ng} / \mathrm{mL}$, clinical stage T1-T2a, and biopsy Gleason sum 6 or less) who select AS have an estimated disease-specific mortality of $1 \%$ at 8 years. ${ }^{14}$ (See Table 2 ) 
Table 2 Preliminary outcomes of active surveillance

\begin{tabular}{|c|c|c|c|c|c|}
\hline Author & Eligibility criteria & Criteria for intervention & Median age & $\begin{array}{l}\text { Median } \\
\text { follow-up }\end{array}$ & DSS \\
\hline Dall-Era, et al ${ }^{13}$ & $\begin{array}{l}\text { TI-I, GS } \leq 6 \\
\mathrm{PSA}<10 \mathrm{ng} / \mathrm{mL} \\
\% \text { positive cores }<33 \%\end{array}$ & $\begin{array}{l}\mathrm{GS} \geq 7, \text { increase } \\
\mathrm{PSA} \text { or tumor volume }\end{array}$ & $63 \mathrm{yrs}$ & $43 \mathrm{mos}$ & $100 \%$ \\
\hline $\mathrm{Klotz}^{14}$ & $\begin{array}{l}\text { TIc-T2a, GS } \leq 6 \\
\text { PSA } \leq 10 \mathrm{ng} / \mathrm{mL}\end{array}$ & $\begin{array}{l}\text { PSADT } \leq 3 y r s \\
\text { PSA }>10 \mathrm{ng} / \mathrm{mL} \\
\text { PSAV } 2 \mathrm{ng} / \mathrm{mL} / \mathrm{yr}\end{array}$ & $70 \mathrm{yrs}$ & 72 mos & $99 \%$ \\
\hline
\end{tabular}

Abbreviations: PSA, prostate specific antigen; GS, gleason score; PSADT, PSA doubling time; PSAV, PSA velocity; DSS, disease specific survival.

If a patient progresses on an AS protocol, early intervention can be offered. As noted, delayed intervention does not appear to significantly compromise successful outcomes compared to immediate intervention. Several other studies have also demonstrated that low-risk patients who delayed prostatectomy for medians of 6 and 22 months did not experience more adverse pathologic outcomes nor a compromised curability. ${ }^{15,16}$ Patients need to be counseled that AS, as the name implies, is an active approach to following cancer and to reassure them that, if their tumor shows any sign of biochemical or pathologic progression during follow-up, intervention can be undertaken safely at that time with minimal added risk.

AS allows close follow-up of disease and intervention with curative intent triggered by early signs of disease progression. An accepted definition of suitable candidates for AS has been offered by Epstein and associates. Based on the Hopkins radical prostatectomy experience, preoperative parameters were assessed to predict which patients were likely to harbor cancers with low risk, favorable features. A PSA density (PSAD) $<0.15 \mathrm{ng} / \mathrm{mL}$, clinical stage T2a or less, and no biopsy Gleason grade 4 or 5 led to a $73 \%$ predictive accuracy for favorable disease. ${ }^{17}$ The AS strategy is appropriate for patients who have a life expectancy of less than 10 years and for healthy men 65 years of age or older who have low-volume, low-grade $\mathrm{CaP}$ as noted by Epstein. ${ }^{18}$ This approach avoids the potential complications of definitive therapy. From a quality of life standpoint, possible adverse effects of AS include increased anxiety and patient

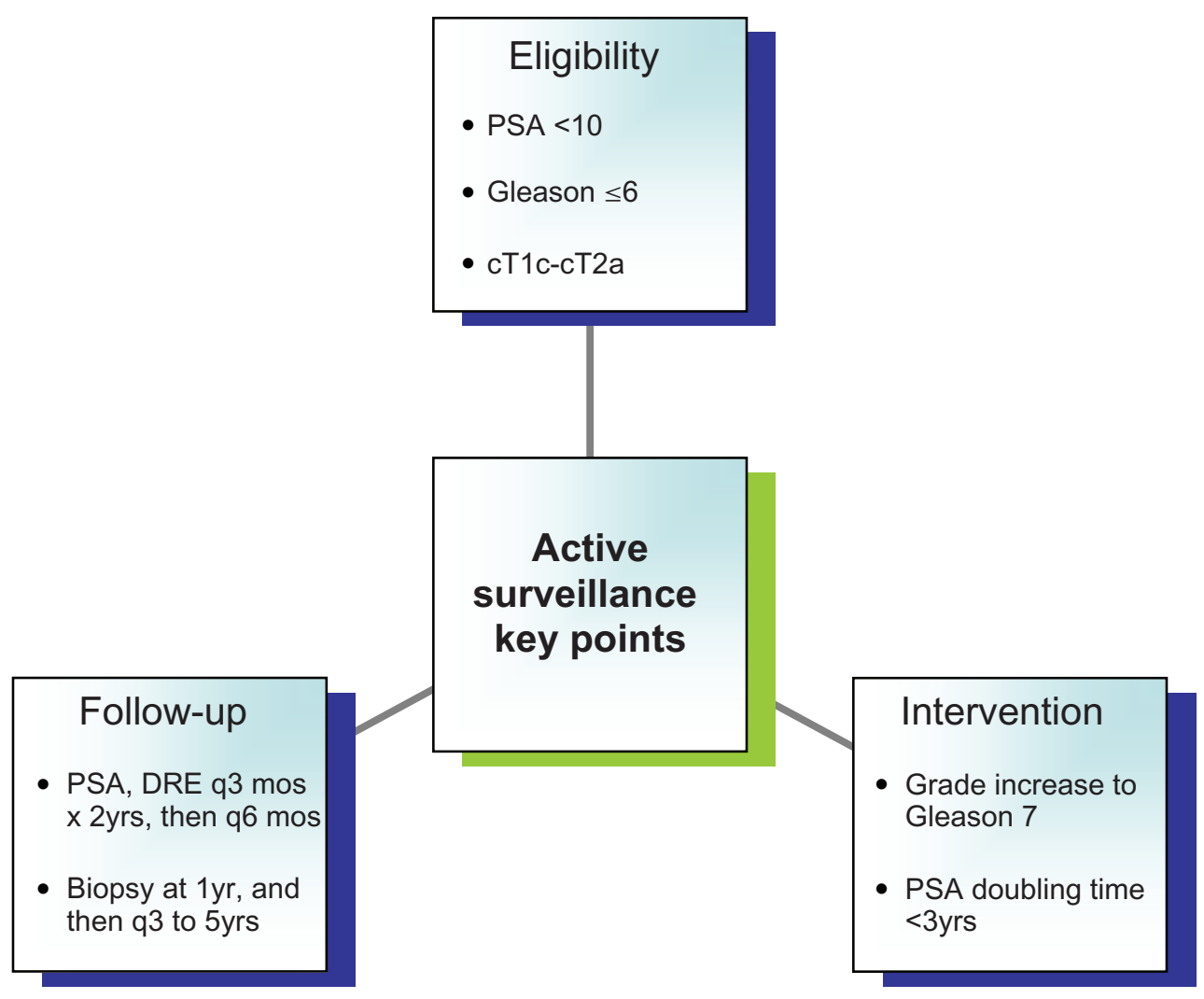

Figure I Summary of active surveillance. 
compliance with repeated prostate biopsies. Clinical progression and loss of the opportunity for definitive "cure", while rare in properly selected men, remains a concern. Patient eligibility into active surveillance, subsequent follow-up, and when to intervene is summarized in Figure 1.

\section{Radical prostatectomy}

One very clear advantage of radical prostatectomy (RP) over other treatment options is precise pathologic staging. As noted, prostate needle biopsy is not entirely accurate, and therefore non-surgical treatment decisions are often made based on Partin or Kattan nomograms. At times, these nomograms may under stage the extent of CaP. For example, extracapsular extension (ECE) has been found in up to $15 \%$ of patients with presumed low risk organ-confined disease. In addition, roughly a third of the patients undergoing prostatectomy will experience a significant upgrade of their Gleason score (upstaging of pattern Gleason 3 to a diagnosis of pattern Gleason 4 or 5). ${ }^{19}$ Following RP, a urologist has clear pathologic data on determining whether the local cancer has been removed, and reassure the patient of a 10 -year disease-free survival of well above $90 \%{ }^{20}$

From a quality of life concern, RP provides the added benefit of an unambiguous interpretation of post-operative PSA, so that a patient can often be reasonably assured that his cancer was removed based on an "undetectable" PSA level (standard PSA assay of $<0.2 \mathrm{ng} / \mathrm{mL}$ ). If the patient's disease is upstaged to pathologic T3 or T4 disease after RP, the patient can be counseled on the use of adjuvant radiation therapy in a timely fashion, which has been shown to reduce the risk of metastasis and improve overall survival. ${ }^{21,22}$ In addition, an inability to achieve an undetectable PSA or a PSA recurrence following RP (PSA $>0.2 \mathrm{ng} / \mathrm{mL}$ ), allows for early therapy in a salvage or an adjuvant fashion. Boorjian et al showed that adjuvant radiotherapy was associated with significantly improved 10-year biochemical recurrence-free survival, local recurrence-free survival and a decreased need for late hormone therapy. ${ }^{23}$ Also, in patients who received salvage radiation, the risk of local recurrence was decreased and systemic progression and hormonal therapy was delayed.

Once again, there is a paucity of clinical trials comparing radical to other treatment modalities. The American College of Surgeons Oncology Group attempted a trial that randomized low risk men between brachytherapy and radical prostatectomy. Due to very poor accrual, the trial was never completed. ${ }^{24}$ One prospective randomized trial has shown a distinct survival advantage of RP over watchful waiting. At 12 years, $12.5 \%$ of the surgery group and $17.9 \%$ of the watchful waiting group had died of $\mathrm{CaP}$, and at 12 years, $19.3 \%$ of men in the surgery group and $26 \%$ of men in the watchful waiting group had been diagnosed with distant metastases. ${ }^{25}$ A retrospective cohort analysis compared oncologic cure rates for RP, external beam radiation therapy (EBRT) and brachytherapy in low-risk CaP. Follow-up of up to 8 years after therapy showed a significant PSA failure-free survival advantage for RP over EBRT (88\% vs 78\%). However, the study has been criticized, as the EBRT patients received on average RT dose of $70 \mathrm{~Gy}$, which is currently considered a low dose, as dose escalation above this level has shown to improve biochemical disease specific survival. ${ }^{26}$ Regardless, long term outcomes after RP are strong with RP considered by most to be the "gold standard" in the treatment of localized $\mathrm{CaP}$.

A recent multi-institutional study of prostate cancer specific mortality (PCSM) after RP at 15 years was $12 \%{ }^{27}$ Results from this study helped establish a nomogram that predicts that only $4 \%$ in the modern PSA era of contemporary patients, had a predicted 15-year PCSM of greater than 5\%. The authors concluded that few patients will die from $\mathrm{CaP}$ within 15 years of radical prostatectomy, even with adverse clinical features. ${ }^{28}$

Excellent outcomes after RP have been reported in older men as well. In patients $>70$ years of age, 10 -year cancerspecific survival rates for low, intermediate and high risk were $99.5 \%, 97.5 \%$ and $94 \%$, respectively. ${ }^{28}$ Postoperative complications in men aged 70-74 years were comparable to the younger cohort of men aged 65-69 years. The rate of complications was only slightly higher in patients 75 years and older. Outcome of RP is related much more to the preoperative comorbidity than to age alone. ${ }^{29} \mathrm{~A}$ life expectancy $>10$ years is the most frequently used benchmark for prostatectomy as definitive therapy for patients with localized $\mathrm{CaP}^{30}$

With its introduction over a decade ago, laparoscopic radical prostatectomy (LRP) challenged the standard retropubic and perineal approaches. LRP has been criticized for its difficult learning curve and its long operating times, allowing only limited centers of excellence to perform this technically demanding operation. Robotic-assisted technology has further allowed the transition of the LRP into the robotically assisted radical prostatectomy RARP. ${ }^{31}$ Now nine years after its approval by the FDA, sixty-three percent of Tier I hospitals own a daVinci surgical system, and the robotic approach accounted for $81 \%$ of all prostate-removal procedures in the US last year. ${ }^{32}$

There are several potential advantages of the robotic approach. RARP is associated with decreased blood loss, and a shorter hospital stay. RARP also appears to afford faster convalescence when compared to the RP, while still 
achieving similar oncologic outcomes. ${ }^{33}$ Although, long term oncologic data is not available yet with RARP, there are numerous series evaluating positive margin rate (PSM), an independent predictive factor for biochemical recurrence. In a review of a comparison of matched-pair analysis of open RP versus RARP, no difference in the PSM rates between RARP and open RP was noted, and the intermediate biochemical progression-free survival was also not significantly different. ${ }^{34}$ By contrast with these results, in a cumulative analysis of six comparative studies reporting data on margins, Ficarra et al showed a statistically significant difference in favor of RARP over open RP. ${ }^{20} \mathrm{~A}$ recent multicenter analysis published in JAMA reviewed the outcomes of about 2,000 men treated with minimally invasive surgical techniques from 2003 to 2007. ${ }^{35}$ They were compared with approximately 6,900 men who had standard open radical prostatectomy. The minimally invasive surgical group had shorter hospital stays and fewer immediate surgical complications compared with open surgery. However, 18 months post operatively, there was a greater risk of incontinence and erectile dysfunction in comparison to the open surgery group. When adjusted for both patient and tumor characteristics, men in both groups required similar amounts of adjuvant therapy. Additional long term studies will be necessary if the claims of improved outcomes of minimally invasive surgery for $\mathrm{CaP}$ will be validated.

As more surgeons learn and perform RARP, it is likely that further modifications will be made at improving outcomes. Kaouk et al have described using laparo-endoscopic single-site surgery (LESS) to perform RP. This technique is performed via a single umbilical incision, with all instruments used through the single site. This is illustrative of the recent shift in surgery to more even more minimally invasive approaches. ${ }^{36}$

Lastly, a comment should be made concerning the major shift in the management of node positive $\mathrm{CaP}$ at the time of radical prostatectomy. Although the classic teaching is that the procedure should be abandoned in the setting of lymph node involvement, recent data including prospective clinical trials and retrospective analysis suggests that this is no longer considered proper management. ${ }^{37,38}$ Overall survival may in fact be improved with the removal of both the prostate, lymph nodes and the immediate use of hormonal therapy. ${ }^{38}$ Data from Messing et al also suggests that a subset of men with positive nodes may have long term disease free survival without additional hormonal therapy. ${ }^{37}$

In conclusion, in order to fully counsel a patient about which surgical modality to choose with regards to complications, oncologic and functional outcomes, a large randomized controlled trial comparing open vs laparoscopic vs robotic-assisted prostatectomy are required but none are currently planned. One factor that has been shown to improve both the cancer control and functional results of radical prostatectomy is the experience of the surgeon, regardless of the technique. ${ }^{39}$

\section{Radiation therapy}

The field of radiation oncology for the treatment of localized $\mathrm{CaP}$ is constantly being reevaluated to optimize delivery and optimize cancer control but also to minimize damage to surrounding normal tissues. Development of better cancer-targeting therapies in the form of three-dimensional conformal radiation therapy (3DCRT) and intensity-modulated radiotherapy (IMRT) and the use of image guided (IGRT) techniques such as fiducial markers theoretically decrease the side effects seen with EBRT. ${ }^{40}$ Similarly, during this same time frame, other advances in the field have supported the use of higher doses of radiation for organ-confined disease and the use of androgen deprivation therapy (ADT) concurrent with EBRT with higher risk tumors.

Data from retrospective analyses suggest that the noted technical improvements translate into decreased rates of local failure and distant metastases, as well as better overall survival. An example of these findings is shown in an analysis of 1,465 men treated in four randomized trials conducted by the Radiation Therapy Oncology Group (RTOG). Radiation doses $>66$ Gy were associated with a $29 \%$ lower relative risk of death from $\mathrm{CaP}$ compared to lower doses. ${ }^{41}$ It is clear that for the treatment of intermediate to high-risk $\mathrm{CaP}$ with radiotherapy high doses are needed for high tumor control. In randomized studies of low dose compared to high dose, a better biochemical control, expressed as PSA-control, was found in favor of the high-dose groups. ${ }^{42,43}$ Multiple trials have demonstrated that doses of 78 to $80 \mathrm{~Gy}$ are needed to obtain definitive therapy for $\mathrm{CaP}$, which is a great increase from the 70 to 74 Gy that was previously the standard of care. ${ }^{43,44}$ As the technology to deliver more accurate RT develops even higher radiation doses are being considered. The RTOG 0126, a large randomized dose escalation trial to look at doses in excess of $81 \mathrm{~Gy}$, recently completed accrual. ${ }^{45}$ Given the fact that dose escalation of RT has shown a survival benefit for men, there is optimism that further dose escalation may benefit patients with high-risk localized disease. Although it is feasible to administer doses in excess of 81 Gy using these techniques, whether doses above 78 Gy provide added benefit for men with low-risk disease remains controversial.

The use of RT in combination with ADT for CaP patients is clearly supported by multiple randomized trials. ${ }^{46,47}$ However, several questions remain unanswered, including the optimal sequenc- 
ing and duration of androgen deprivation. In the RTOG 8610, 471 men were randomly assigned to RT with or without Zoladex plus flutamide. ADT was administered for 2 months before and 2 months during RT. At a median follow-up of 12.5 years, ADT significantly decreased the rates of disease-specific mortality, distant metastases, and biochemical failure (23\% vs 36\%, 35\% vs $47 \%$, and $65 \%$ vs $80 \%$ with and without ADT, respectively) while increasing the rate of disease-free survival (11\% vs $3 \%)^{48}$ D'Amico et al reported a survival benefit with neoadjuvant (NADT) of 6 months in patients with intermediate risk $\mathrm{CaP}^{47}$ The major endpoint of the study was overall survival and the time to PSA $>1.0 \mathrm{ng} / \mathrm{mL}$ and an increase in the PSA by $>0.2 \mathrm{ng} / \mathrm{mL}$ on two consecutive occasions. Patients randomized to receive NADT had a significantly improvement in overall survival, cause specific survival and survival without salvage ADT. One drawback in these studies is that the dose of RT delivered would be considered suboptimal by today's standards, and therefore would ADT provide benefit in current patients receiving higher radiation doses? Therefore, some investigators have argued that if adequate local doses are given ADT may not be required. ${ }^{49}$

Another area of advancement has been with the use of prostate markers to allow for an accurate guide in delivering RT. Our experience from the Kimmel Cancer Center has shown that placement of gold fiducial markers can easily be placed in an outpatient setting, more importantly, these markers allowed accurate delivery of RT while limiting acute toxicity. ${ }^{40}$ Investigators at the University of California San Francisco (UCSF) have shown that prostate markers provide an accurate guide such that treatments can be delivered within $2 \mathrm{~mm}$, without the risk of seed migration. ${ }^{50}$ This progression has allowed the development in the field of image guided radiotherapy (IGRT) and 4D CRT. The "fourth dimension" in this setting refers to the impact of time on the position and/or shape of the target volume allowing tight margins that can be placed around the target tissues.

Monotherapy with radioactive seeds is preferably reserved for patients with low-risk disease, many groups are combining seed brachytherapy with EBRT for patients with intermediate to high-risk disease. The goal of this approach is to aim at higher tumor dose and better coverage of the target volume because of presumed extension of cancer cells beyond the prostate boundaries. The advantage of multi-modal RT is also seen in high-dose-rate brachytherapy in conjunction with IMRT over IMRT alone. The 3-year biochemical disease-free survival rates in high-risk patients treated with IMRT alone was $67 \%$ as opposed to $93 \%$ in the high dose rate (HDR) brachytherapy and IMRT group. ${ }^{51}$ The same benefit has also been shown in intermediate and high-risk patients who received 3DCRT with a single HDR brachytherapy implant over 3DCRT. The 5- and 7-year biochemical control rates for intermediate were $82.5 \%$ and $80.3 \%$, respectively, for the combined group and $81.3 \%$ and $71 \%$, respectively, for 3DCRT alone. In addition, there was minimal toxicity in patients with unfavorable $\mathrm{CaP}$ who underwent combination therapy. ${ }^{52}$

Stereotactic body radiotherapy is being rapidly deployed in the treatment of localized $\mathrm{CaP}$. The prostate target is usually localized in space using an external frame of reference which can be related to the treatment machine. Stereotactic positioning can be precise and as a result, stereotactic radiotherapy commonly employs higher doses per fraction and fewer fractions (hypofractionation) than conventional radiation. Stereotactic body radiotherapy typically consists of a total course of therapy comprising five or fewer treatments. Many commercially available systems are currently used that typically incorporate some type of sophisticated image guidance and most also have patient immobilization devices (eg, CyberKnife ${ }^{\circledR}$ Robotic Radiosurgery System, Accuray, Inc., Sunnyvale, CA and many others). The utility of hypofractionation in the treatment of $\mathrm{CaP}$ is not conclusive and awaits the results of ongoing randomized trials to confirm any of the hypofractionation advantages over routinely administered (normofractionated) radiotherapy. ${ }^{53}$

Proton beam, or charged-particle beam, radiotherapy for CaP was first used at Massachusetts General Hospital in the 1970s, but recently has received increased attention in press for the treatment of CaP. In theory, proton particles have better depth penetration than traditional photon or electron beam therapy and therefore, should deposit most of their energy near the tumor site rather than at the skin level. In addition, very little of the prescribed dose travels past the site of tumor, whereas, photons continue to deposit the dose of radiation in normal tissues beyond the tumor. This phenomenon is known as Bragg peak, where the pattern of delivery is localized with a sharp drop off past the projected site of delivery. ${ }^{54}$

In a phase II trial comparing the dosimetric characteristics of protons and IMRT, Vargas et al showed a decrease of 59\% and $35 \%$ of the rectal and bladder dose, respectively. ${ }^{54}$ Proton beam therapy is expected to deliver biologically equivalent doses more precisely and with less radiation-induced morbidity than conventional photon radiation therapy. It is unclear whether the claimed high precision in dose delivery is beneficial, let alone necessary, for the treatment of $\mathrm{CaP}$ when compared to contemporary radiation techniques.

\section{Cryotherapy}

Cryotherapy has been used for surgical lesions since the 1850's, when it was first introduced by Dr James Arnot. ${ }^{55}$ The American 
Urologic Association (AUA) recognized cryotherapy first in 1996 for the treatment of CaP. Although, only recently, the AUA has accepted cryosurgery as a primary modality in treatment of localized CaP, published in Best Practice Statement on Cryosurgery for the Treatment of Localized Prostate Cancer. ${ }^{56}$ Cryotherapy is currently indicated in low-risk patients as an alternative to prostatectomy or radiotherapy, in higher-surgicalrisk patients as primary therapy, and in patients who have not responded to radiation therapy as a salvage procedure.

Historically, cryosurgery was associated with relatively high risks, such as urethral sloughing, rectal injury and urinary fistulas. Major advances have occurred in the delivery of cryotherapy in the past 15 years. A significant development was the introduction of cryotherapy probes that use argon gas rather than liquid nitrogen. Argon rapidly cools the probe tip to $-187^{\circ} \mathrm{C}\left(-304.6^{\circ} \mathrm{F}\right)$ and can be rapidly exchanged with helium at $67^{\circ} \mathrm{C}\left(152.6^{\circ} \mathrm{F}\right)$ for an active thawing phase, producing a faster response to operator input and significantly speeding 2-cycle treatment. ${ }^{57}$ Moreover, argon-based probes have a much smaller diameter, thus permitting direct, sharp transperineal insertion, facilitating more conformal cryosurgery.

Gland volume is an important factor: larger prostates may be more difficult to treat because of the difficulty in achieving a uniformly cold temperature throughout the gland. Neoadjuvant therapy for downsizing the gland may be considered in such patients, although there are no published studies on this topic.

With the newer generation of cryoprobe needles, urethral and rectal warming catheters, real-time temperature monitoring, the rates of complications have been drastically improved. In a review of current literature, the rates of incontinence, urethral fistula, and urethral sloughing are reported to be $2 \%-7 \%, 0 \%-2 \%$, and $2 \%-6 \%$, respectively. ${ }^{58,59,60}$ Han et al reported good outcomes in a series of 106 patients with only 3\% incontinence requiring pads, $5 \%$ urge incontinence requiring no pads, $3.3 \%$ transient urinary retention, and $2.6 \%$ rectal pain..$^{59}$ This demonstrates the relatively low complication profile of cryotherapy. Short of any head to head trials, in terms of being minimally invasive, the side-effect profile of cryoablation is comparable to EBRT and brachytherapy. Moreover, in a study by Hubosky et al at 18-month follow-up, cryosurgery patients had better urinary function compared with a series of brachytherapy patients, and this improvement was still present at 24 months. ${ }^{58}$ Robinson et al presented quality of life (QoL) outcomes from a single institution randomized trial comparing EBRT with cryotherapy for localized $\mathrm{CaP}$. Cryoablation patients reported lower urinary function scores (69.4 vs 90.7), similar bowel function, and lower sexual function scores (7.2 vs 32.9). At 36 months EBRT men had slightly lower urinary function scores but no difference in bowel function scores. The cryoablation patients had lower sexual function scores at 36 months (16 vs 36.7). ${ }^{61}$

One major downside to cryosurgery is the high risk of erectile dysfunction. This occurs primarily because the effective "kill zone" to ensure adequate prostatic coverage extends to the periprostatic tissue, which includes the neurovascular bundle, necessary for erection. Hubosky et al reported that only $20 \%$ of the entire cohort was able return to baseline sexual function at 12 -month followup. ${ }^{58}$ This is similar to other published studies that report the incidence of ED after total gland cryosurgery, to be nearly 90 percent of patients at 1 year of follow-up. ${ }^{59,60}$ Therefore, patients for whom preservation of erectile function is a high priority are probably less-than-ideal candidates.

One of the drawbacks of cryotherapy, similar to RT, is that post intervention monitoring of recurrent disease or failure of treatment can be difficult. Most commonly, similar to post RT patients, PSA is followed but the definition of biochemical failure is not universally defined. The two definitions, ASTRO criteria and the Phoenix criteria, described in EBRT data are implemented in the cryotherapy literature. Others have used a strict PSA cutoff. However, the nadir PSA cutpoint that should represent the absence of cancer remains uncertain. Long-term retrospective data from Cohen et al reported 10-year biochemical Disease Free Survival (bDFS) of 56.01\% according ASTRO criteria and $62.36 \%$ using the Phoenix criteria (nadir plus $2 \mathrm{ng} / \mathrm{mL}$ ). When stratified by risk groups (low, medium, and high), bDFS using the Phoenix criteria was $80.56 \%, 74.16 \%$, and $45.54 \%$, respectively. ${ }^{62}$

Jones et al recently published the largest series of patients undergoing whole gland cryotherapy as primary treatment, all of whom were included in the Cryo On-Line Database (COLD) registry the largest cohort published regarding whole gland cryotherapy for localized $\mathrm{CaP}$. The median pretreatment PSA level was $6.8 \mathrm{ng} / \mathrm{mL}$ (mean, $9.6 \pm 8.6 \mathrm{ng} / \mathrm{mL}$ ), and various Gleason scores were represented (median, 7). The mean follow-up period was $24.4 \pm 25.9$ months. Applying the Phoenix definition to the data from men accumulated in that registry, 91 percent of men with low-risk, 78 percent of men with intermediate-risk, and 62 percent of men with high-risk, localized $\mathrm{CaP}$ experienced biochemical recurrence. ${ }^{63}$

The COLD registry is a multicenter collaboration, was developed and incorporates data from four academic medical centers and 34 community urologists, so that control of the generation of cryosystem used and treatment protocols varied among different centers. This inherently weakens the data as there is no standardization in deliver- 
ing the treatment modality. More importantly, $49.5 \%$ of these men received hormone therapy prior to cryoablation, perhaps giving a false undetectable PSA. ${ }^{63}$ Regardless, published data from the COLD registry report 5-year bDFS of $77.1 \%$ using the ASTRO criteria and $72.9 \%$ using the Phoenix criteria. Using risk stratification, the 5-year bDFS was $84.7 \%, 73.4 \%$, and $75.3 \%$ (ASTRO) and $91.1 \%, 78.5 \%$, and $62.2 \%$ (Phoenix) for low-, medium-, and high-risk groups, respectively. ${ }^{63}$

As discussed earlier, incidence of ED is high in patients undergoing whole gland ablation. Although still in experimental stages, focal cryoablation, or commonly coined term the "male lumpectomy" of the prostate is developing as a potential option for patients with unilateral, low-risk cancer. The goal behind

Table 3 Comparison of some prostate cancer treatment options for localized disease

\begin{tabular}{|c|c|c|}
\hline Treatment & Benefits & Limitations \\
\hline $\begin{array}{l}\text { Active surveillance/watchful } \\
\text { waiting }\end{array}$ & $\begin{array}{l}\text { - Avoids treatment of insignificant cancer } \\
\text { - Not risks of side effects from surgery } \\
\text { or radiation }\end{array}$ & $\begin{array}{l}\text { - Potential "anxiety" from not treating a diagnosed cancer } \\
\text { - Regular rectal exams, PSA testing with periodic/multiple } \\
\text { biopsy to monitor } \\
\text { - Possibility that "window of curability" may be missed }\end{array}$ \\
\hline Radical prostatectomy & $\begin{array}{l}\text { - Accurate pathologic staging } \\
\text { - Allows PSA to be more reliable marker } \\
\text { of disease control } \\
\text { - Trials demonstrate reduction in prostate } \\
\text { cancer specific deaths } \\
\text { - Allows potential for nerve sparing procedure } \\
\text { - Long term outcome data available (for open } \\
\text { radical prostatectomy) } \\
\text { - Compared to radiation treatments, less issues } \\
\text { with urinary frequency or urgency, rectal and } \\
\text { bowel irritation } \\
\text { - Salvage possible with EBRT }\end{array}$ & $\begin{array}{l}\text { - Surgical risks (infection, bleeding, reaction to anesthesia, etc) } \\
\text { - For laparoscopic/robotic technique: additional risk of } \\
\text { intrabdominal injury or pneumoperitoneum related } \\
\text { complications; limited long term outcome data at present } \\
\text { - Limited physical activity in recovery period ( } 2-4 \text { weeks) } \\
\text { - Post op complications of incontinence: } 5 \%-20 \% \text { (usually } \\
\text { stress); erectile dysfunction: up to } 50 \% \text { at } 5 \text { years (with nerve } \\
\text { preservation, may be improved by medical therapy); bladder } \\
\text { neck contractures } 1 \%-3 \% \text {; lymphocele with retropubic } \\
\text { approach; rare rectal injury }\end{array}$ \\
\hline $\begin{array}{l}\text { External beam radiation } \\
\text { therapy (EBRT) } \\
\text { (normofractionation) }\end{array}$ & $\begin{array}{l}\text { - Avoids hospital stay and risk of surgery } \\
\text { - Outpatient, limited impact on daily living } \\
\text { - Long term cancer control reported } \\
\text { - Addition of hormonal therapy improved } \\
\text { cancer control for high risk } \\
\text { - Incontinence rare ( } 1 \%-2 \%) \\
\text { - Urinary retention less common than with } \\
\text { brachytherapy }\end{array}$ & $\begin{array}{l}\text { - No post-treatment staging information } \\
\text { - Daily treatments for } 6-8 \text { weeks } \\
\text { - Fatigue may occur when treatment ends } \\
\text { - Erectile dysfunction: up to } 50 \% \text { at } 5 \text { years } \\
\text { - Bowel/rectal problems: } 5 \%-10 \% \text { (urgency, pain, diarrhea, or } \\
\text { bleeding) but typically improve after treatment } \\
\text { - Bladder irritation: } 5 \% \text { (urinary frequency, urgency, discomfort) } \\
\text { - Salvage therapies limited or associated } \\
\text { with high complication rate }\end{array}$ \\
\hline $\begin{array}{l}\text { Stereotactic body } \\
\text { radiotherapy } \\
\text { (hypofractionation) }\end{array}$ & $\begin{array}{l}\text { - "Convenient" outpatient treatments } \\
\text { as short as five days }\end{array}$ & - Utility and side effect profile not well studied \\
\hline Brachytherapy & $\begin{array}{l}\text { - Minimal surgical risks, one time outpatient } \\
\text { surgical procedure } \\
\text { - Best for low risk prostate cancer } \\
\text { - Delivers higher dose to prostate target, } \\
\text { less to surrounding tissues } \\
\text { - Long term data available } \\
\text { - Low rate of incontinence }(1 \%-2 \%)\end{array}$ & $\begin{array}{l}\text { - Not useful for intermediate or high risk cancer } \\
\text { - Very small and very large glands ( }<20 \mathrm{cc},>80 \mathrm{cc}) \text { challenging } \\
\text { - No final pathologic staging } \\
\text { - Less favorable option for men with intermediate- or high-risk } \\
\text { disease } \\
\text { - Not recommended for men with significant lower urinary } \\
\text { tract symptoms } \\
\text { - Urinary tract side effects (retention, urgency, frequency) more } \\
\text { common than with other therapies } \\
\text { - ED outcomes similar to EBRT } \\
\text { rate }\end{array}$ \\
\hline Proton beam therapy & $\begin{array}{l}\text { - Ability to deliver dose to prostate } \\
\text { and avoid other structures }\end{array}$ & $\begin{array}{l}\text { - Most costly infrastructure of all treatments } \\
\text { - No trials to demonstrate superiority over current radiation } \\
\text { modalities } \\
\text { - Limited number of facilities }\end{array}$ \\
\hline Cryotherapy & $\begin{array}{l}\text { - One time treatment, often outpatient } \\
\text { - Can be repeated } \\
\text { - Allows for potential "focal" therapy }\end{array}$ & $\begin{array}{l}\text { - No final pathology } \\
\text { - Side effect profiles can be difficult to manage, but improving } \\
\text { with newer techniques } \\
\text { - High rate of ED for whole gland therapy }\end{array}$ \\
\hline
\end{tabular}


focal therapy is to allow effective tumor ablation while sparing the neurovascular bundle. Onik et al reported their result of forty-eight patients with a mean follow-up of 4.5 years, who had focal cryoablation. Forty-five of 48 patients (94\%) had stable PSAs, using the ASTRO criteria, with no evidence for cancer. Twenty-four patients who underwent routine biopsy had no evidence of disease. ${ }^{64}$

Focal cryoablation may therefore have a potential role for low-risk patients with unilateral disease on biopsy who are desirous of preserving erectile function. A study by Ward et al reviewed prostate specimens with unilateral positive prostate biopsy to characterize the location, volume and grade of each tumor focus, in determining if focal therapy templates could eradicate tumor burden. Despite only $17 \%$ of patients having a single focus of cancer, hemi-prostate treatment templates that would have been used in focal therapy would have successfully treated all clinically significant prostate tumor foci in $81 \%$ of patients. Most out-of-field cancers were clinically insignificant tumors not identified by prostate biopsy (lowvolume, $0.5 \mathrm{~mL}$; and low grade, Gleason score $<$ or $=6$ ). ${ }^{65}$ Contemporary results of focal cryotherapy demonstrate high-potency rates of approximately $90 \%{ }^{64,66}$

\section{Other treatment modalities}

High intensity focused ultrasound (HIFU) is approved in the EU and in Canada but is not commercially available in the US. High dose rate radiation (HDR) employs temporary prostate implantation that requires a short hospital stay. It is usually done in combination with external beam radiation therapy. At present data is limited on this approach and the number of facilities that perform prostate cancer HDR in the US is limited.

Many elderly men with localized $\mathrm{CaP}$ receive only hormonal therapy. However, the benefit of hormonal monotherapy (LHRH analogue alone, LHRH in combination with antiandrogens or with antiandrogens alone) in localized cancer is not clear and can be associated with severe toxicities in some men. ${ }^{67}$ Treatment guidelines do not recommend its use as a first-line therapy at earlier disease stages. Despite limited evidence to date for the impact on clinical outcomes, the use hormonal monotherapy therapy in patients with localized or locally advanced $\mathrm{CaP}$ has increased in many countries, most notably Japan. ${ }^{68}$ Hormonal therapy, either using LHRH analogues alone or in combination with antiandrogens is currently controversial in localized $\mathrm{CaP}$ as a monotherapy and should not be used routinely until additional data is available.

\section{Conclusion}

As illustrated in this paper, there are numerous treatment options available for the management of localized CaP. At the present time, there is no single correct or "best" option for all men. The limited availability of head to head randomized trials makes picking the right treatment option more difficult. The trend for patients seeking multidisciplinary clinical consultations are often facilitated at cancer centers with a commitment to these patient centric efforts. ${ }^{69}$

As noted by the AUA, various factors must be taken into consideration when making a collective decision in the man with clinically localized $\mathrm{CaP}^{70}$ Consideration for enrolling the patient in a randomized trial is always a top priority as we move the care of our patients ahead. The comparisons of the risks and benefits of treatments for localized $\mathrm{CaP}$ and $\mathrm{AUA}$ recommendations are summarized in Tables 3 and 4. Quality of life factors such as potency, urinary, or rectal bother should play an important role in any patient's treatment decision and a detailed discussion of these specific issues is beyond the scope of this paper. A recent publication by Sanda, et al provides excellent objective data on the potential major quality of life effects of primary CaP treatment. ${ }^{71}$

Outcomes for men with low risk disease treated by radiation or surgery appear to have similar cancer outcomes out to at least $10-15$ years. Perhaps, the younger patient with greater than ten year life expectancy may benefit from accurate staging and an undetectable PSA offered by RP. With high risk disease, adjuvant radiation administered as part of a multimodality treatment plan following prostatectomy may improve biochemical recurrence and possibly overall survival. Radiation combined

Table 4 Treatment options for localized prostate cancer based on guidelines from the American Urologic Association ${ }^{70}$

\begin{tabular}{lll}
\hline Risk classification & Treatment options & Notes \\
\hline Low & AS, IR, EBRT, RP, WW & $\begin{array}{l}\text { Review patient preferences on QOL issues } \\
\text { High RT dose may decrease PSA recurrence } \\
\end{array}$ \\
Intermediate & IR, EBRT, RP, WW & $\begin{array}{l}\text { No data to support superiority } \\
\text { Six month HT + RT }\end{array}$ \\
High & EBRT, RP, WW & Multimodal approach to treatment \\
& & Adjuvant and concurrent HT with RT \\
\hline
\end{tabular}

Abbreviations: AS, active surveillance; IR, interstitial radiotherapy; EBRT, external beam radiotherapy; RP, radical prostatectomy; WW, watchful waiting. 
with hormonal therapy is currently considered standard of care for those men with high risk features who opt for external beam radiation therapy. A patient interested in one single minimally invasive intervention may seek brachytherapy or cryotherapy. Finally, a suitable patient for AS may choose this less invasive route to monitor his $\mathrm{CaP}$. In the end, the treatment of $\mathrm{CaP}$ needs to be individualized for each patient, after weighing in the current information available to each patient's expectations, overall health and quality of life.

\section{Disclosure}

The authors report no conflicts of interest in this work.

\section{References}

1. Schwartz R. Management of Prostate Cancer - Polling Results. NEngl J Med. 2009 Jan;15;360(3):e4.

2. Hernandez DJ, Nielsen ME, Han M, et al. Contemporary evaluation of the D'amico risk classification of prostate cancer. Urology. 2007 Nov; 70(5):931-935.

3. Shariat SF, Karakiewicz PI, Roehrborn, et al. An updated catalog of prostate cancer predictive tools. Cancer. 2008 Dec;113(11):3075-3099.

4. D'Amico AV, Chen MH, Roehl KA, et al. Preoperative PSA velocity and the risk of death from prostate cancer after radical prostatectomy. N Engl J Med. 2004 Jul:351(2):125-135.

5. Dall'Era MA, Konety BR, Cowan JE, et al. Active surveillance for the management of prostate cancer in a contemporary cohort. Cancer. 2008 Jun;112(12):2664-2670.

6. Yin M, Bastacky S, Chandran U, et al. Prevalence of incidental prostate cancer in the general population: A study of healthy organ donors. J Urol. 2008 Mar;179(3):892-895.

7. Ries LA, Melbert D, Krapcho M, et al editors. SEER Cancer Statistics Review, 1975-2005. Based on 2007 Nov SEER data submission, posted to the SEER website, 2008. Bethesda, Md, National Cancer Institute. Available at http://seer.cancer.gov/csr/1975_2005.

8. Parker C, Muston D, Melia J, et al. A model of the natural history of screen-detected prostate cancer, and the effect of radical treatment on overall survival. Br J Cancer. 2006 May;94(10):1361-1368.

9. Schroder FH. Screening for prostate cancer (PC)-an update on recent findings of the European Randomized Study of Screening for Prostate Cancer (ERSPC). Urol Oncol. 2008 Sep-Oct;26(5):533-541.

10. Davis JW, Kim J, Ward JF, et al. Radical prostatectomy findings in patients predicted to have low-volume/low-grade prostate cancer diagnosed by extended-core biopsies: an analysis of volume and zonal distribution of tumour foci. BJU Int. Article in Press.

11. van den Bergh RC, Roemeling S, Roobol MJ, et al. Outcomes of men with screen-detected prostate cancer eligible for active surveillance who were managed expectantly. Eur Urol. 2009 Jan;55(1):1-8.

12. Eggener SE, Mueller A, Berglund RK, et al. A multi-institutional evaluation of active surveillance for low risk prostate cancer. J Urol. 2009 Apr;181(4):1635-1641.

13. Dall-Era MA, Konety BR, Cowan JE, et al. Active surveillance for the management of prostate cancer in a contemporary cohort. Cancer. 2008 Jun;112(12):2664-2670.

14. Klotz L. Active surveillance for favorable risk prostate cancer: What are the results, and how safe is it? Semin in Rad Oncol. 2008 Jan;18(1): $2-6$.

15. Freedland SJ, Kane CJ, Amling WJ, et al. Delay of radical prostatectomy and the risk of biochemical progression in men with low risk prostate cancer. J Urol. 2006 Apr;175(4):1298-1302.

16. Warlick C, Trock BJ, Landis P, et al. Delayed versus immediate surgical intervention and prostate cancer outcome. J Natl Cancer Inst. 2006 Mar;98(5):355-357.
17. Bastian PJ, Carter BH, Bjartell A, et al. Insignificant prostate cancer and active surveillance: From definition to clinical implications. Eur Urol. 2009 Jun;55(6):1321-1330.

18. Walsh PC, DeWeese TL, Eisenberger MA. Clinical practice. Localized prostate cancer. N Engl J Med. 2007 Dec;357(26):2696-2705.

19. Grossfeld GD, Chang JJ, Broering JM, et al. Under staging and under grading in a contemporary series of patients undergoing radical prostatectomy: Results from the Cancer of the Prostate Strategic Urologic Research Endeavor database. J Urol. 2001 Mar;165(3):851-856.

20. Ficarra V, Novara G, Artibani W, et al. Retropubic, laparoscopic, and robot assisted radical prostatectomy. A systematic review and cumulative analysis of comparative studies. Eur Urol. 2009 May;55(5):1037-1063.

21. Thompson IM, Tangen CM, Paradelo J, et al. Adjuvant radiotherapy for pathological T3N0M0 prostate cancer significantly reduces risk of metastases and improves survival: Long-term followup of a randomized clinical trial. J Urol. 2009 Mar;181(3):956-962.

22. Trabulsi EJ, Valicenti RK, Hanlon AL, et al. A multi-institutional matched-control analysis of adjuvant and salvage postoperative radiation therapy for pT3-4N0 prostate cancer. Urology. $2008 \mathrm{Dec}$; 72(6):1298-1302.

23. Boorjian SA, Karnes RJ, Crispen PL, et al. Radiation Therapy After Radical Prostatectomy: Impact on Metastasis and Survival. J Urol. 2009 Dec;182(6):2708-2714.

24. Wallace K, Fleshner, Jewett M, et al. Impact of a multi-disciplinary patient education session on accrual to a difficult clinical trial: the Toronto experience with the surgical prostatectomy versus interstitial radiation intervention trial. J Clin Oncol. 2006 Sep;24(25):4158-4162.

25. Bill-Axelson A, Holmberg L, Filen F, et al. Radical prostatectomy versus watchful waiting in localized prostate cancer: The Scandinavian prostate cancer group-4 randomized trial. J Natl Cancer Inst. 2008 Aug;100(16):1144-1154.

26. D'Amico AV, Whittington R, Malkowicz SB, et al. Biochemical outcome after radical prostatectomy or external beam radiation therapy for patients with clinically localized prostate carcinoma in the prostate specific antigen era. Cancer. 2002 Jul;95(2):281-286.

27. Stephenson AJ, Kattan MW, Eastham JM, et al. Prostate cancer-specific mortality after radical prostatectomy for patients treated in the prostatespecific antigen era. J Clin Oncol. 2009 Sep;27(26):4300-4305.

28. Siddiqui SA, Sengupta S, Slezak JM, et al. Impact of patient age at treatment on outcome following radical retropubic prostatectomy for prostate cancer. J Urol. 2006 Mar;175(3):952-957.

29. Begg CB, Riedel ER, Bach PB, et al. Variations in morbidity after radical prostatectomy. $N$ Engl J Med. 2002 Apr;346(15):1138-1144.

30. Walz J, Gallina A, Saa F, et al. A Nomogram Predicting 10-Year Life Expectancy in Candidates for Radical Prostatectomy or Radiotherapy for Prostate Cancer. J Clin Oncol. 2007 Aug;25(24):3576-3581.

31. Trabulsi EJ, Zola JC, Gomella LG, et al. Transition from pure laparoscopic to robotic-assisted radical prostatectomy: A single surgeon institutional evolution. Urol Oncol. $2010 \mathrm{Jan}-\mathrm{Feb} ; 28(1): 81-85$.

32. CNBC.com http://www.cnbc.com/id/31112735 Published 2009 June, accessed Nov 2009.

33. Frota R, Turna B, Barros R, et al. Comparison of radical prostatectomy techniques: open, laparoscopic and robotic assisted. Int Braz J Urol. 2008 May-Jun;34(3):259-268.

34. Coelho RF, Chauhan S, Palmer KJ, et al. Robotic-assisted radical prostatectomy: a review of current outcomes. BJU Int. 2009 Nov; 104(10):1428-1435.

35. Ficarra V, Novara G, Artibani W, et al. Retropubic, laparoscopic, and robot assisted radical prostatectomy. A systematic review and cumulative analysis of comparative studies. Eur Urol. 2009 May;55(5):1037-1063.

35. Hu JC, Gu X, Lipsitz SR, et al. Comparitive Effectiveness of Minimally Invasive vs Open Radical Prostatectomy. JAMA. 2009 Oct; 302(14):1557-1564.

36. Kaouk JH, Goel RK, Haber GP, et al. Single-port laparoscopic radical prostatectomy. Urology. 2008 Dec;72(6): 1190-1193. 
37. Messing EM, Manola J, Yao J, et al. Immediate versus deferred androgen deprivation treatment in patients with node-positive prostate cancer after radical prostatectomy and pelvic lymphadenectomy. Lancet Oncol. 2006 Jun;7(6):472-479.

38. Engel J, Bastian PJ, Baur H, et al. Survival Benefit of Radical Prostatectomy in Lymph Node - Positive Patients with Prostate Cancer. Eur Urol. Article in Press.

39. Eastham JA. Do high-volume hospitals and surgeons provide better care in urologic oncology? Urol Oncol. 2009 Jul-Aug;27(4):417-421.

40. Linden RA, Weiner PR, Gomella LG, et al. Technique of outpatient placement of intraprostatic fiducial markers before external beam radiotherapy. Urology. 2009 Apr;73(4):881-886.

41. Valicenti R, Lu J, Pilepich M, et al; Survival advantage from higherdose radiation therapy for clinically localized prostate cancer treated on the Radiation Therapy Oncology Group trials. J Clin Oncol. $2000 \mathrm{Jul}$; 18(14):2740-2274.

42. Peeters ST, Heemsbergen WD, Koper PC, et al. Dose - response in radiotherapy for localized prostate cancer: results of the Dutch multicenter randomized phase III trial comparing 68 Gy of radiotherapy with 78 Gy. J Clin Oncol. 2006 May;24(13):1990-1996.

43. Zietman AL, DeSilvio, Slater JD, et al. Comparison of conventionaldose vs high-dose conformal radiation therapy in clinically localized adenocarcinoma of the prostate: a randomized controlled trial. JAMA. 2005 Sep;294(10):1233-1239.

44. Pollack A, Zagars GK, Starkschall G, et al. Prostate cancer radiation dose response: Results of the Anderson MD phase III randomized trial. Int J Radiat Oncol Biol Phys. 2002 Aug;53(5):1097-1105.

45. http://clinicaltrials.gov/ct2/show/NCT00033631 Accessed Nov 2009.

46. Pilepich MV, Winter K, John MJ, et al. Phase III Radiation Therapy Oncology Group (RTOG) trial 86-10 of androgen deprivation adjuvant to definitive radiotherapy in locally advanced carcinoma of the prostate. Int J Radiat Oncol Biol Phys. 2001 Aug;50(5):1243-1252.

47. Roach M 3rd. Dose escalated external beam radiotherapy versus neoadjuvant androgen deprivation therapy and conventional dose external beam radiotherapy for clinically localized prostate cancer: do we need both? Strahlenther Onkol. 2007 Dec;183 Spec No 2:26-28.

48. Roach M 3rd, Bae K, Speight J, et al. Short-term neoadjuvant androgen deprivation therapy and external-beam radiotherapy for locally advanced prostate cancer: Long-term results of RTOG 8610. J Clin Oncol. 2008 Feb;26(4):585-591.

49. Jacob R, Hanlon AL, Horwitz EM, et al. Role of prostate dose escalation in patients with greater than $15 \%$ risk of pelvic lymph node involvement. Int J Radiat Oncol Biol Phys. 2005 Mar;61(3):695-701.

50. Pouliot J, Aubin M, Langen KM, et al. (Non)-migration of radiopaque markers used for on-line localization of the prostate with an electronic portal imaging device. Int J Radiat Oncol Biol Phys. 2003 Jul;56(3):862-866.

51. Wilder RB, Barme GA, Gilbert RF, et al. Preliminary results in prostate cancer patients treated with high-dose-rate brachytherapy and intensity modulated radiation therapy (IMRT) vs IMRT alone. Brachytherapy. Article in Press. Accessed Nov 2009.

52. Zwahlen DR, Andrianopoulos N, Matheson B, et al. High-dose-rate brachytherapy in combination with conformal external beam radiotherapy in the treatment of prostate cancer. Brachytherapy. Article in Press. Accessed Nov 2009.

53. Macías V, Biete A. Hypofractionated radiotherapy for localized prostate cancer. Review of clinical trials. Clin Transl Oncol. 2009 Jul; 11(7):437-445.

Clinical Interventions in Aging

\section{Publish your work in this journal}

Clinical Interventions in Aging is an international, peer-reviewed journal focusing on evidence-based reports on the value or lack thereof of treatments intended to prevent or delay the onset of maladaptive correlates of aging in human beings. This journal is indexed on PubMed Central, MedLine, the American Chemical Society's 'Chemical
54. Vargas C, Fryer A, Mahajan C, et al. Dose-volume comparison of proton therapy and intensity-modulated radiotherapy for prostate cancer. Int J Radiat Oncol Biol Phys. 2008 Mar;70(3):744-751.

55. Gage AA. History of cryosurgery. Semin Surg Oncol. 1998 Mar; 14(2):99-109.

56. Babaian RJ, Donnelly B, Bahn D, et al. Best practice statement on cryosurgery for the treatment of localized prostate. J Urol. 2008 Nov; 180(5):1993-2004.

57. Cytron S, Greene D, Witzsch, et al. Cyroablation of the Prostate: Technical Recommendations. Prostate Cancer Prostatic Dis. 2009 Dec; 129(4):339-346

58. Hubosky SG, Fabrizio MD, Schellhammer PF, et al. Single center experience with third generation cryosurgery for management of organ-confined prostate cancer: critical evaluation of short-term outcomes, complications and patient quality of life. J Endourol. 2007 Dec; 21(12):1521-1531.

59. Han KR, Cohen JK, Miller RJ, et al. Treatment of organ confined prostate cancer with third generation cryosurgery: preliminary multicenter experience. J Urol. 2003 Oct;170(4 Pt 1):1126-1130.

60. Polascik T, Nosnick I, Mayes J, et al. Short-term cancer control after primary cryosurgical ablation for clinically localized prostate cancer using third generation cryotechnology. Urology. 2007 Jul;70(1):117-121.

61. Robinson JW, Donnelly BJ, Siever JE, et al. A randomized trial of external beam radiotherapy versus cryoablation in patients with localized prostate cancer: quality of life outcomes. Cancer. 2009 Oct;115(20):4695-4704.

62. Cohen JK, Miller RJ, Ahmed S, et al. Ten-year biochemical disease control for patients with prostate cancer treated with cryosurgery as primary therapy. Urology. 2008 Mar;71(3):515-518.

63. Jones JS, Rewcastle JC, Donnelly B, et al. Whole gland primary prostate cryoablation: initial results from the cryo on-line data registry. $J$ Urol. 2008 Aug;180(2):554-558.

64. Onik G, Vaughan D, Lotenfoe R, et al. The "male lumpectomy": focal therapy for prostate cancer using cryoablation results in 48 patients with at least 2-year follow-up. Urol Oncol. 2008 Sep-Oct;26(5):500-505.

65. Ward JF, Nakanishi H, Pisters L, et al. Cancer ablation with regional templates applied to prostatectomy specimens from men who were eligible for focal therapy. BJU Int. 2009 Aug;104(4):490-497.

66. Bahn DK, Silverman P, Lee FSr, et al. Focal prostate cryoablation: initial results show cancer control and potency preservation. J Endourol. 2006 Sep;20(9):688-692.

67. Heinzer H, Steuber T. Prostate cancer in the elderly. Urol Oncol. 2009 Nov;27(6):668-672.

68. Akaza H. Future Prospects for Luteinizing Hormone-Releasing Hormone Analogues in Prostate Cancer Treatment. Pharmacology. 2010 Feb; 85(2):110-120.

69. Valicenti RK, Gomella LG, El-Gabry EA, et al. The multidisciplinary clinic approach to prostate cancer counseling and treatment. Semin Urol Oncol. 2000 Aug;18(3):188-191.

70. Thompson I, Thrasher JB, Aus G, et al. Guideline for the management of clinically localized prostate cancer: 2007 update. J Urol. 2007 Jun; 177(6):2106-2131.

71. Sanda MG, Dunn RL, Michalski J, et al. Quality of life and satisfaction with outcome among prostate-cancer survivors. N Engl J Med. 2008 Mar;358:1250-1261.

Abstracts Service' (CAS), Scopus and the Elsevier Bibliographic databases. The manuscript management system is completely online and includes a very quick and fair peer-review system, which is all easy to use. Visit http://www.dovepress.com/testimonials.php to read real quotes from published authors. 